\title{
1 An improved decision model for evaluating risks in construction projects
}

2 Morteza Yazdani ${ }^{1}$, M Reza Abdi ${ }^{2}$, Niraj Kumar ${ }^{3 *}$, Mehdi Keshavarz-Ghorabaee ${ }^{4}$ and Felix T. S. Chan $^{5}$

4

${ }^{1}$ Universidad Loyola Andalucai, 41014, Seville, Spain.

email: myazdani@uloyola.es

${ }^{2}$ Bradford School of Management, Emm Lane, Bradford, BD9 4JL, United Kingdom.

email:R.Abdi@bradford.ac.uk

$9 \quad{ }^{3}$ University of Liverpool Management School, Chatham Street, Liverpool L69 7ZH, United Kingdom email:niraj.kumar.dr@gmail.com

${ }^{4}$ Department of Industrial Management, Faculty of Management and Accounting, Allameh Tabataba'i

email: m.keshavarz_gh@yahoo.com

${ }^{5}$ Department of Industrial and Systems Engineering, Hong Kong Polytechnic University, Hung Hom, 
28 The paper develops an innovative risk evaluation methodology to address the challenges of multi-

29 criteria decision-making problem of project evaluation and selection. The methodology considers Fuzzy Analytic Network Process (FANP) to incorporate the inter-dependencies of different risk

31 factors, and Failure Mode and Effect Analysis to conduct the rating analysis of projects to develop the 32 decision matrix. Finally, evaluation based on the distance from average solution compares alternative 33 projects and reports the optimal solution. The proposed approach allows project managers to engage 34 in the evaluation process and to use fuzzy linguistic values in the assessment process. A case study 35 from the construction sector is selected to verify the efficacy of the proposed approach over other 36 popular approaches in literature.

37 Keywords: Multi-criteria decisions; Failure mode and effect analysis; Fuzzy analytical network 38 process; Risk assessment; Construction projects. 


\section{Introduction}

In industrial projects, the risk assessment exercise has strategic importance, and can decide the success or failure of the project. Risk assessment involves the analysis of the whole project in order to reduce the impact of potential risk factors. It begins by identifying the potential risks that could influence the project. During the project planning phase, the project manager usually forms a team of experts and relevant stakeholders to assess the potential risk factors that could affect the successful completion of the project. The team uses techniques like brainstorming, discussions and tools such as flowcharts, root cause analysis, histogram and cause-effect analysis to release potential problems. Several tools are utilized by different risk management teams to develop the risk-breakdown structure and risk-profile. This paper is primarily focused on the risk evaluation and assessment of construction projects.

Scenario analysis is one of the most popularly used techniques for evaluating project risks. The project team evaluates the impact of each risk factor in terms of the probability of its occurrence and the influence on the project. A structured approach is needed to recognize potential / known failure modes at different levels of the project and investigate the effect on the next sub-system level (Sharma et al. 2005). Failure Mode and Effect Analysis (FMEA) is considered as a fundamental tool and a part of the risk assessment methodology in several studies, and is established as one of the most reliable techniques (Dinmohammadi and Shafiee, 2013). This technique can help in understanding different failure modes within a system, evaluating their impacts, and deciding for corrective actions (Abdelgawad and Fayek, 2010). However, reported applications of this technique in the construction industry are limited (Andery et al., 2000; Nielsen, 2002). Evaluating different risk factors in construction projects is a complex task since the objective functions may change during the project life cycle (Dikmen et al. 2008). Further, Tserng et al. (2009) discussed an ontology based risk management framework for construction projects based on the project life cycle variance and covariance. However, FMEA provides a better approach to assess the severity of a potential risk, and by identifying the "risk priority" of a project, the key stakeholders can adopt a suitable risk management strategy to manage 
potential risks (Safari et al. 2016). In practice, it is necessary to address technical, external and internal (organizational) issues through a risk breakdown structure. When developing this structure, it is important to reduce the chance of a risk event being missed, and to develop a comprehensive view of the project.

\section{Research significance}

Multi-criteria decision-making $(\mathrm{MCDM})$ techniques are amongst the most efficient approaches to evaluate risk factors and assist in real-life decision problems. In recent years, there is growing trend in integrating different MCDM approaches to develop hybrid techniques with better performance to address risk assessment problems in different projects (Chan and Kumar 2007; Chan et al. 2008; Chang 2013; Prakash and Barua, 2016). It enables experts to be flexible in choosing relevant methods and creating integrated structures. Past literature (such as Gu and Zhu 2006; Tzeng et al. 2007; Yang and Tzeng, 2011; Liu et al. 2012; Liu et al. 2013) have provided further evidence to support the novelty of integrated and hybrid methods in order to take the advantage of two or more decision making approaches.

Moreover, Franceschini and Galetto (2001) presented a multi-expert MCDM model to analyze the risk preferences of failures in FMEA. In this model, risk factors were transformed as evaluation criteria, while failure modes were considered as different alternatives to be decided. This method contemplated each decision-making criterion as a fuzzy subset over the set of alternatives. Chin et al. (2009) discussed a FMEA model using the group-based evidential reasoning (ER) approach to collate diverse opinions and prioritize failure modes under uncertainties such as incomplete assessment, ignorance and intervals. Hu et al. (2009) developed a green component risk priority number to analyze the risks involved due to hazardous substances. In their study, Fuzzy analytic hierarchy process (FAHP) was used to identify the relative weights of risk factors. Then the green component risk priority number (RPN) was calculated for each component to assess the risks derived from them. In this study, the 
91 application of fuzzy value FMEA in the context of risk evaluation is discussed, where FMEA forms

92 an initial decision matrix for evaluation process.

93 The novelty of the proposed approach lies in the way it analyzes the anatomy of a project framework.

94 One of the important activities in decision modelling is to find logical ways to weigh different decision 95 attributes. In past literature, mostly Analytic hierarchy process (AHP), Delphi and entropy based 96 approaches are used to determine the weights of different influencing factors. However, in many 97 decision problems, the decision criteria are strictly dependent on each other. Analytic network process 98 (ANP) is the method that undertakes the interrelationship of risk factors in a ratio scale and aids in 99 overcoming the drawbacks of the decision levels and clusters (Tavana et al. 2016). The advantages of 100 ANP can be summarized as follows (Ignatius et al. 2016) : 1) ANP converts qualitative values into 101 numerical values for relative analysis of preferences, 2) It has a simple and intuitive structure, and 3) 102 it allows the participation of stakeholders and experts in the decision process.

103 In addition, risk evaluation in real life problems usually confronts low levels of information and 104 certainty. In the literature, the fuzzy approach is recognized as an effective tool for tackling uncertainty 105 stemming from inaccurate information (Wang et al. 2009). In multi-criteria decision-making problems, 106 where some of the criteria cannot be quantitatively represented, the fuzzy set theory can be helpful to 107 enable project assessors to express their linguistic preferences, and to convert those preferences into 108 numerical values for comparative analysis (Ho et al. 2012). He et al. (2015) studied the complexity of 109 mega construction projects in China using Fuzzy ANP methodology and argued that the methodology 110 can help decision makers to develop effective strategy for the project execution.

111 In this paper, an integrated decision-making approach, combining ANP and FMEA in a fuzzy 112 environment is proposed for the risk evaluation process. Very limited studies are available in the 113 literature which attempt to integrate FMEA and ANP with fuzzy variables for risk assessment. 114 Additionally, the 'evaluation based on the distance from the average solution' (EDAS) method is 
115 adopted to compare alternative projects and rank them based on risk priority. A case study is also

116 discussed to explain the implementation process of the proposed approach.

117 The rest of the paper is organized as follows: Next section discusses the proposed integrated approach

118 (combining fuzzy set theory, ANP and FMEA) for risk assessment. Further, the case study and risk 119 management methodology are presented, along with the analysis and findings. The managerial 120 implications of the proposed approach is also discussed. At the end, paper concludes with a discussion 121 on future research directions.

\section{Research Background}

123 This section discusses different methods for addressing multi-criteria decision-making problems.

124 Particular attention has been given to approaches that are closely related to the integrated approach for 125 risk evaluation proposed in this paper.

\section{$126 \quad$ Fuzzy set theory}

127 In real world decision problems, there are many instances where decision makers are faced with multiple criteria when reaching to a decision. However, estimating the impact of these criteria on potential decision outcomes is cumbersome, and this sometimes results in extremely pessimistic or optimistic decisions being made. In every decision environment two types of systems can be proposed

131 based on the availability of information. In white systems, all internal information is completely 132 known, whereas in a black system, it is difficult to obtain any information and characteristics about the 133 system (Zavadskas et al. 2010). Saaty (1980) introduced the analytic hierarchy process (AHP) to 134 accurately represent the consensus of experts and is one of the most widely applied methods in practical 135 applications. In his study, the geometric mean is used as the reference for triangular fuzzy numbers. 136 Zadeh (1965) provided the fuzzy set theory for dealing with the uncertainty due to imprecise and vague 137 information. The theory also allows mathematical operations and programming to be applied in the 138 fuzzy domain. A fuzzy set is a class of objects with a continuum of grades of membership (degree of compatibility) (Peng and Selvachandran 2017). Such a set is characterized by a membership function, 
140 which reflects the degree of compatibility assigned to each object with the grade of membership

141 between 0 and 1.

142 A triangular fuzzy number (TFN) is defined simply as $(l, m, u)$ where parameters $l$, $m$, and $u$ represent

143 the smallest possible value, the most promising value and the largest possible value that denotes a

144 fuzzy event. The triangular fuzzy numbers $\tilde{a}_{i j}$ can be established as:

$145 \tilde{a}_{i j}=\left(l_{i j}, m_{i j}, u_{i j}\right)$

$146 \quad l_{i j} \leq m_{i j} \leq u_{i j}, l_{i j}, m_{i j}, u_{i j} \in(0,1)$

147 To establish the fuzzy pair-wise comparison matrix, the following procedure must be followed:

148 Suppose $\tilde{A}=\left[\tilde{a}_{i j} \mid\right.$ denotes a triangular fuzzy number for depicting the relative importance of criteria $C_{1}$

$149, C_{2}, \ldots C_{n}$. In this way, $\tilde{a}_{i j}$ represents a matrix constructed by triangular fuzzy numbers.

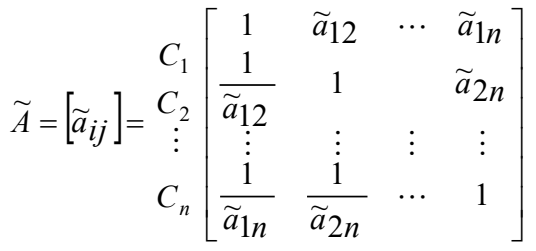

151 Defuzzification is a technique to convert the fuzzy number into crisp real numbers and the procedure

152 of defuzzification is to locate the Best Non-fuzzy Performance (BNP) value (Tsaur and Wang 2007).

153 Methods such as the Mean-of-Maximum, the Centre-of-Area, and the $\alpha$-cut method are the most

154 common defuzzification approaches. In this research, fuzzy risk criteria are defuzzified with the help 155 of the Centre-of-Area method. This was chosen due to its simplicity and its less reliance on the personal 156 judgement of analysts. A defuzzified value of a TFN can be produced using the equation below:

$157 \quad \mathrm{BNP}=\left[\left(U_{i j}-L_{i j}\right)+\left(M_{i j}-L_{i j}\right)\right] / 3+L_{i j}$

\section{Fuzzy $A N P$}

160 ANP is a popular MCDM technique useful to deal with interdependency of complex decision factors.

161 It helps decision makers (DMs) to define complex relationships among several decision levels and 
162 their corresponding attributes (Saaty 1996). It helps in overcoming the drawbacks of AHP in 163 addressing interrelationships issues among different decision levels using a super-matrix which detects 164 the composite weights (Shyur, 2006; Kang et al. 2012).

165 By structuring the problem as an ANP model, the uncertain vague elements of matrix A used for pair166 wise comparisons can be redefined by fuzzy membership functions reflecting the degree of 167 compatibility for both the quantitative and the qualitative criteria. By pair-wise comparisons using a 168 fuzzy membership function e.g. with triangular fuzzy numbers, the fuzzy pair-wise comparison matrix $169 \tilde{A}$ with elements $\tilde{a}_{i j}$, is constructed where $\tilde{a}_{i j}=\left(l_{i j}, m_{i j}, u_{i j}\right)$ reflects the influence of element i over 170 element $\mathrm{j}$ that could be a criterion/alternative in the network with lower $\left(l_{i j}\right)$, mean $\left(m_{i j}\right)$ and higher $171 u_{i j}$ values respectively. The value $u_{i j}-l_{i j}$ could reflect the domain/degree of fuzziness. The greater 172 that $u_{i j}-l_{i j}$ is, the fuzzier the degree is. When $u_{i j}-l_{i j}=0$, the judgment is a non-fuzzy number (crisp 173 value) with $m_{i j}$ importance value. Contrarily, assuming that $\tilde{A}$ is a positive $\mathrm{n} \times \mathrm{n}$ reciprocal matrix, $174 \tilde{a}_{i j}=\tilde{a}_{i j}{ }^{-1}=\left(\frac{1}{u_{i j}}, \frac{1}{m_{i j}}, \frac{1}{l_{i j}}\right)$ that represents influence of element $j$ over element $i$ with lower $\frac{1}{u_{i j}}$, mean $\frac{1}{m_{i j}}$ 175 , and higher $\frac{1}{l_{i j}}$ values respectively. As a result, the fuzzification increases the complexity of the 176 computation for synthesis judgments based on the fuzzy elements $a_{i j} s$. To be able to evaluate a fuzzy

177 ANP model through standard pair-wise comparisons, the fuzzy values are standardized into a single178 pattern fuzzy set dealing with both linguistic and/or quantifiable criteria (Abdi, 2009). Accordingly, 179 the importance weights are defined with five triangular fuzzy sets: 1,3,5,7,9 with their 180 corresponding lower, mean, and upper values defined in equation (5) and represented in Table 1 (Abdi and Labib, 2004). 
182

The fuzzy range of $(1,3,5,7,9)$ are used to express linguistic preferences for evaluation criteria in terms of Equal (EQ), Low (L), Medium (M), High (H), and Very High (VH) as decision linguistic variables (Table 1), respectively. EQ can also represent equal to very low importance. If criterion $\left(\mathrm{c}_{\mathrm{i}}\right)$ is assigned one of the fuzzy numbers above when compared with criterion $\left(c_{j}\right)$, then $c_{j}$ has the reciprocal value when compared with $\mathrm{c}_{\mathrm{i}}$. To simplify the weighting process, the priority values are put in a reciprocal comparison bar for each pair of attributes with respect to a criterion/alternative. For example, if value 5 is assigned on the right-hand side criterion $\left(c_{j}\right)$, then criterion $c_{j}$ is more important than $c_{i}$ with a moderate degree. Similarly, if value 5 is assigned on the left criterion $\left(c_{i}\right)$, then the criterion $c_{i}$ is more important than $c_{j}$ with a moderate degree (Abdi and Labib, 2004).

The synthesized fuzzy degree of criterion $\mathrm{i}$ influenced by criterion $\mathrm{j}$, where $i, j=1,2, \ldots, n$, each with a triangular fuzzy number $\tilde{a}_{i j}$ in an ANP structure, can be derived from formula (5). In the ANP with a $(n \times n)$ super-matrix, in which any element can influence on another element based on the influence flow from a component/cluster to another component/cluster, or from a component to itself (inner dependency loop), the number of elements influencing on or being influenced by criterion i could be up to $\mathrm{n}$ elements. In the fuzzy environment, the comparison ratios $\tilde{a}_{i j}$ are represented by the membership functions that indicate the degree of compatibility/possibility. 


\section{Fuzzy FMEA}

Failure mode and effects analysis (FMEA) is a risk measurement tool, which is used in various engineering and management problems such as project risk management. Accordingly, a risk priority number (RPN) is constructed for measuring key risk elements and prioritizes several risky problems/projects, for which the largest RPN corresponds to the riskiest problem/project being considered. The purpose of this section is to explain the logic and shortcomings of RPN values.

In the FMEA, risk value is evaluated by grading the data according to key risk elements: 1) severity of effect (S), 2) frequency of occurrence (P), and 3) detectability (D). The multiplied sum of these figures produces the risk priority number. Failure mode and effects analysis extends the risk priority matrix that includes RPN for each project:

$$
\mathrm{RPN}=\text { Severity } \times \text { Probability } \times \text { Detection }
$$

In typical RPN problems, a rating of 1 to 10 on each scale will be assigned to each risk element, with 10 being severe, very likely to occur, and impossible to detect. These ratings are then multiplied together to obtain RPN values, which are used to assess the projects. The idea is that the problem with the highest $R P N$ value is the critical one (with a highest priority) that needs to be focused on. However, there are two logical difficulties with calculating the RPN. As argued by Wheeler (2011), multiplication of the RPN elements is nonsense; with having assigned a range of 1 to 10 to each element, RPN varies from 1 to 1,000 with only 125 possible values, which are not uniformly distributed between 1 and 1,000. In the typical RPN, the three elements are assumed to be of the same importance while being given crisp values ranging from 1 to 10 . RPN values gained from multiplication of the three elements are not meaningful because each value is an interval scale and not a ratio scale as a requirement for multiplication. However, in a ratio scale, the values can be ordered with consistently identical distance between two values (the distance between 1 and 3 is the same of the distance between 5 and 7 , and etc.), and with an absolute zero point (starting from zero rather than 1). 
230 To overcome the shortcomings of using certain value and illogical multiplication, the elements can be 231 considered as linguistic values ranging from Very Low (VL), Low (L), Medium (M), High (H), and 232 Very High (VH) respectively. By using RPN linguistic scores, 125 problem descriptions $\left(5^{3}\right)$ can be 233 obtained; each with the 5 options above e.g. a risk score of HMH (High, Medium High) reflect values 234 of (Severity, Occurrence, Detectability) respectively. So far, all the values for RPN elements are 235 assumed to be crisp ranging in [1,5]. Conversely, the elements can be considered as criteria with fuzzy 236 number as described earlier. Therefore, the fuzzy range of $(\hat{1}, 3, \hat{5}, \hat{7}, \hat{9})$ can be used to express 237 linguistic priorities. Using fuzzy number ranging from $\hat{1}, \hat{3}, \hat{5}, \hat{7}$, to $\hat{9}$, each problem description can 238 be seen as a fuzzy linguistic value, and a ratio fuzzy scale can be achieved by a synthesized fuzzy 239 number. Adopting from the extent analysis (Chang, 1996), the synthesized result for criterion i will 240 remain fuzzy as shown in formula (7).

$241 \quad S_{i}=\sum_{j=1}^{n} \tilde{a}_{i j} \otimes\left(\sum_{i=1}^{n} \sum_{j=1}^{n} \tilde{a}_{i j}\right)^{-1}=\left(l_{s i}, m_{s i}, u_{s i}\right) ; \quad i, j=1,2, \ldots, n$

$242 \quad \mathrm{~V}(\mathrm{M} \geq \mathrm{L})=$ supreme $_{\mathrm{x} \geq \mathrm{y}}\left[\min \mu_{\mathrm{L}}(\mathrm{x}), \mu_{\mathrm{M}}(\mathrm{y})\right]$

243 Where $V$ is the possibility of $M \geq L$ and a pair (x,y) exists, If $x \geq y$ and $\mu_{L}(x)=\mu_{M}(y)=1$, then $V(M$ $244 \geq \mathrm{L})=1$ where $\mathrm{V}$ is the possibility distribution. Considering $\mathrm{M}$ and $\mathrm{L}$ are convex fuzzy numbers

$245(l, m, u)$ and $\mathrm{L}=(1,3,5)$ and $\mathrm{M}=(3,5,7)$ :

$246 \quad \mathrm{~V}(\mathrm{M} \geq \mathrm{L})=1 \quad$ as $\mathrm{m}_{\mathrm{M}}=5$ and $\geq \mathrm{m}_{\mathrm{L}}=3$

$247 \quad \mathrm{~V}(\mathrm{~L} \geq \mathrm{M})=\mu_{\mathrm{L}}(\mathrm{d})=\mathrm{D}=0.5$

248 D is equal to $\mu(d)$, and $d$ is the intersection point of two sides of triangles of fuzzy number M and $\mathrm{L}$.

249 we have:

250 Line 1: $\mathrm{p} 1:(5,0), \mathrm{p} 2:(3,1)$ then $(\mathrm{Y}-0) /(1-0)=(\mathrm{X}-5) /(3-5)$ then $-2 \mathrm{Y}=\mathrm{X}-5$

251 Line 2: p1: $(3,0), \mathrm{p} 2:(5,1)$ then $(\mathrm{Y}-0) /(1-0)=(\mathrm{X}-3) /(5-3)$ then $2 \mathrm{Y}=\mathrm{X}-3$ 
252 Value ' $d$ ' can be found by equalizing the simultaneous equations by adding equations for Line 1 and

253 line 2, therefore:

$2540=2 X-8$, then $X=4$ so, $d=4$, and therefore by substituting $d$ in Line 1 or Line 2 :

$255 \quad \mathrm{Y}=\mathrm{D}=0.5$, therefore:

$256 \mathrm{~V}(\mathrm{~L} \geq \mathrm{M})=0.5$

257 Interestingly, the degree possibility for $\mathrm{M} \geq \mathrm{L}$ equals 1 whereas it is 0.5 for $\mathrm{L} \geq \mathrm{M}$.

258 We also have:

$\mathrm{V}(\mathrm{L} \geq \mathrm{M}, \mathrm{H}, \mathrm{VH})=\mathrm{V}(\hat{1} \geq \hat{3}$ and $\hat{5}$ and $\hat{7}$ and $\hat{9})=\operatorname{Min}(\mathrm{V}(\mathrm{L} \geq \mathrm{M}), \mathrm{V}(\mathrm{L} \geq \mathrm{H})$ and $\mathrm{V}(\mathrm{L} \geq \mathrm{VH})=\mathrm{V}($

261 That means the fuzzy number 1 (Low) cannot be greater than fuzzy values $(\mathrm{M}, \mathrm{H}, \mathrm{VH})$ at once as the

262 degree possibility is zero.

263 The synthesized fuzzy number for caparison matrix $\tilde{A}$ can be derived using formula (14):

264 Fuzzy RPN = Fuzzy Severity $(\mathrm{S}) *$ Fuzzy Occurrence $(\mathrm{P}) *$ Fuzzy Detection (D)

265 To avoid the logical failure of the multiplication of the three risk elements Severity (S), Occurrence

266 (P), and Detection (D) in obtaining RPN the linguistic scales can be replaced for ranking projects with regards to their risks and the impacts. As shown in Table 2, the risk values can be classified to 5 fuzzy numbers which reflect the linguistic scales with fuzzy range possibility for each scale. By ordering of these three risk aspects, a fuzzy RPN value for each project with combination of three fuzzy numbers

270 for three risk elements is allocated. All the possible combinations will be $125(=5 * 5 * 5)$ with different 271 scores which can be ordered based on their centred average in a descending order to see the most 272 critical (risky) projects at the top of the table. In this approach, equal importance is given to each risk 273 element.

274 The final rating will range from extremely high $(\mathrm{EXH})$, very high $(\mathrm{VH})$, high $(\mathrm{H})$, medium $(\mathrm{M})$, low 275 (L) and very low (VL). The combinations of the three elements in a descending order from EXH, VH, 
276 to $\mathrm{H}$ are presented in Appendix 1. combinations from 125 possible combinations are ranked from $\mathrm{H}$ to

277 EXH. The same combination of elements is defined for medium (M), low (L) and very low (VL). The 278 table presented in Appendix 1 facilitates the collection of data related to pair-wise comparison of risks 279 factors and sub-factors from the group of experts and decision makers.

280

\section{Evaluation based on distance from average solution (EDAS) method}

In order to solve the MCDM problems, the alternatives must be ranked by computing the distance of the possible solutions from the ideal and worst solutions using the EDAS tool (Ghorabaee et al. 2015). The most preferred alternative will have the lowest distance from ideal solution and the highest distance from the nadir solution in VIKOR and TOPSIS methods (Yazdani and Payam, 2015). However, in the proposed approach, the best alternative is related to the distance from the average solution $(A V)$. This method does not need to calculate the ideal and the nadir solution, instead two measures dealing with the desirability of the alternatives will be computed. The first measure is the positive distance from average (PDA), and the second is the negative distance from average (NDA). These measures can illustrate the difference between each solution (alternative) and the average solution. As suggested by Ghorabaee et al. (2016), the evaluation of alternatives is made according to the higher values of PDA and lower values of NDA.

$$
<<\text { Insert Table } 2 \text { about here }>>
$$

The EDAS ranking score can be obtained as follows (Ghorabaee et al. (2016):

Step 1 - Select the most relevant attributes, which describe the alternatives for the specific decision problem. 
299 Step 2 - Let $x_{i j}$ be the performance rating of $i^{\text {th }}$ alternative $A_{1}, A_{2}, \ldots, A_{n},(i=1,2, \ldots ., n)$ with respect to the $300 j^{\text {th }}$ criterion $C_{1}, C_{2}, \ldots, C_{m}(j=1,2, \ldots, m)$. Form the interval decision matrix $X$ and weight of each 301 criterion $\mathrm{W}$ as follows:

$302 \quad X=\left[x_{i j}\right]_{n \times m}=\left[\begin{array}{cccc}x_{11} & x_{12} & \ldots & x_{1 m} \\ x_{21} & x_{22} & \ldots & x_{2 m} \\ \cdot & \cdot & \cdot & \cdot \\ \cdot & \cdot & . & . \\ \cdot & . & . & . \\ x_{n 1} & x_{n 2} & . . & x_{n m}\end{array}\right]$,

$303 W=\left[w_{1}, w_{2}, \ldots, w_{m}\right]$

304 For $(i=1,2, \ldots ., n)$ and $(j=1,2, \ldots, m)$

305 where $w_{j}$ is the weight of criterion $j^{\text {th }}$

306 Step 3 - The average solution with respect to all criteria must be determined as shown following the 307 formula:

$308 \quad A V_{j}=\frac{\sum_{i=1}^{n} x_{i j}}{n}$;

309 Step 4 - The positive distance from average $(P D A)$ and the negative distance from average $(N D A)$

310 matrices can be calculated as:

$311 P D A_{i j}=\frac{\max \left(0,\left(x_{i j}-A V_{j}\right)\right)}{A V_{j}}$

$312 N D A_{i j}=\frac{\max \left(0,\left(A V_{j}-x_{i j}\right)\right)}{A V_{j}}$

313 In this way $P D A_{i j}$ and $N D A_{i j}$ represent the positive and negative distance of the ${ }_{i}$ th alternative from the

314 average solution in terms of the $j^{\text {th }}$ criterion for the lower level of decision matrix, respectively.

315 Step 5 -Compute the weighted summation of the positive and negative distances from the average 316 matrix: 
$317 S P_{i}=\sum_{j=1}^{m} w_{j} P D A_{i j}$

$318 \quad S N_{i}=\sum_{j=1}^{m} w_{j} N D A_{i j}$

319 Step 6 - Find the normalized values of $S P_{i}$ and $S N_{i}$ for all alternatives as follows:

$320 N S P_{i}=\frac{S P_{i}}{\operatorname{Max}_{i}\left(S P_{i}\right)}$

$321 \quad N S N_{i}=1-\frac{S N_{i}}{\operatorname{Max}_{i}\left(S N_{i}\right)}$

322 Step 7 - Calculate the appraisal score $A S$ for all alternatives as:

$323 A S=\frac{1}{2}\left(N S P_{i}+N S N_{i}\right)$,

324 where $0 \leq A S \leq 1$

325 Step 8 - Rank the alternatives according to the decreasing values of the appraisal score ( $A S)$. The 326 alternative with the highest $A S$ is the best choice.

327

328

329

\section{Problem context and proposed approach}

Projects' failure could be the result of poor planning of risk management and a lack of proper risk analysis (Kerzner, 2001). On the other hand, risk management could be seen as a cost-containment tool rather than a systematic process and technique for handling various aspects of the projects (Zwikael and Globerson, 2006). It has been shown that risk management incorporates cost, time, quality and scope are unavoidably connected and interdependent ( Lavender 2013, Mantel et al. 2011; Chan et al. 2004). Therefore, if the risk management is considered for controlling cost, then it is similarly concerned with controlling time, quality and scope that could result in successful project delivery.

In the past, clients or contractors rarely formally requested risk analysis for their projects (even for infrastructural projects) (Akintoye and MacLeod 1997). An independent investigation undertaken by 
British Airports Authority (BAA) indicates that any UK construction project with over $£ 1$ billion in value for construction over 10 years, in addition to all international airport projects completed in the previous 15 years, had not been delivered on time, on budget, safely or met their specified quality standards (Lowe 2013). Due competitive environment for contracting projects, customers are now able to get involved with project, insisting contractors to assume higher levels of risk through various types of contracts: Lump sum, Guaranteed Maximum Price (GMP), or Not-To-Exceed price (NTE). With increasing project size, complexity and competition, the management of risks, particularly at the early stage of the project is becoming an ever more important challenge (Maytorena et al. 2007). Therefore, it is crucial to improve both organizational and project performance with developing risk assessment methodologies that can be mutually accepted as a critical component of successful project delivery (PwC, 2013; KPMG and PMI 2012).

The proposed model integrates analytical network process (ANP) and, failure mode and effect analysis (FMEA) with fuzzy approach in order to develop a meaningful and practical solution to the project risk evaluation problem. These three methods have been integrated to complete three tasks: ANP to weight decision criteria, FMEA to shape the performance-rating matrix (decision table), and the outputs of these two methods are used as input to EDAS (third method) which produces the ranking of the projects considering the risk factors. Each method has its particular advantage, and the intelligent integration of them provides a robust methodology for risk evaluation.

The proposed model to evaluate construction projects based on risk variables can be presented in three phases (Figure 1):

Phase I - In the first phase, a team of experts will define the risk attributes, decision alternatives and level of complexity. In this phase, the proposed integrated model will be explained to the experts.

Phase II - The second phase based on the ANP principles represents the relationship and interaction among the decision variables and constructs the pairwise comparison matrix (shown in Figure 2). The fuzzy ANP utilizes this matrix to estimate weights of the decision factors and sub-factors. Further in 
this phase, the initial risk matrix for alternative projects is decided through a new fuzzy FMEA scoring,. Three decision makers (DMs) present their views over projects considering risk determination values. The fuzzy FMEA procedure is explained earlier in the paper. The outputs of this phase will be the input (weights of the attributes and performance rating of projects) of phase III.

$<<$ Insert Figure 1 about here $>>$

Phase III - At last, in the third phase, the EDAS method (as described earlier) evaluates projects and ranks them from the best to worst. Comparisons with other MCDM methods and sensitivity analysis are performed in order to test the consistency and stability of the results.

\section{Implementation of the proposed approach}

In this section, the implementation process of the proposed approach is discussed. Six projects considered in this study are medium to large scale construction projects. These projects are related to building water reservoirs and dams in one of the European countries. Due to the lack of rain and decreasing water resources, the need to construct water reservoirs and dams to improve water availability for agriculture is one of the important issues in this country. All of these projects are from different regions of the country with varying degree of resources availability, weather conditions, geographical features and political situations. Assessing and measuring the risks in developing these construction projects are vital for the successful completion of the projects. Also for planning purpose, it is important to understand the risks involved due to limited resources available for these projects. The risk evaluation of these construction projects in this study is based on measuring the risks with the help of the proposed decision analysis model and then rate them according to different risk parameters. The proposed approach is implemented in consultation with the practitioners and planners to understand the real -life challenges in risk evaluation of constructions projects. 
391 Phase I - This study examines the hierarchical risk breakdown structure (RBS) for risk assessment of construction projects. Organizations use RBS in conjunction with Work Breakdown Structure (WBS) to help management team and eventually analyze risks (Mantel et al. 2011). For the six construction projects, specific risks must be identified and analyzed. In this phase, ANP tool is used to produce the weights of risk factors and sub factors. ANP is an applied tool in MCDM which considers the interrelationship among risk elements using pairwise comparison. The ANP network (Figure 2) presents the criteria and sub-criteria for the risk assessment of the construction projects. Different decision variables for risk evaluation in construction projects are identified based on past literature such as Antuchevičiene et al. (2010) and Zavadskas et al. 2010). However, these factors and sub-factors are later verified during the interviews with the key decision makers in the construction projects. The risk factors in this study are classified into three groups : a) Technical, b) External and c) internal / organisational risk factors. The technical factors include: $\mathrm{C}_{1}$ ) construction requirements; $\mathrm{C}_{2}$ ) technology; $\mathrm{C}_{3}$ ) complexity and interfaces; $\mathrm{C}_{4}$ ) quality and $\mathrm{C}_{5}$ ) cost; external factors include $\mathrm{C}_{6}$ ) subcontractors and suppliers; $\mathrm{C}_{7}$ ) economic and market; $\mathrm{C}_{8}$ ) weather; and $\mathrm{C}_{9}$ ) political; and internal factors include $\mathrm{C}_{10}$ ) resources; $\mathrm{C}_{11}$ ) funding; and $\mathrm{C}_{12}$ ) project site. Later on, the pairwise comparisons among different decision factors and sub-factors are performed, which help to get global weighs of each factors and sub-factors to decide the final risk assessment of the projects. The project risk ratings are determined using fuzzy linguistic variables.

Phase II - In order to obtain the weights of factors and sub-factors using ANP, the pairwise comparison matrix must be performed between factors and sub-factors. To shape the global weight matrix for all

412 the factors, primarily pairwise comparison must be made between each factor and sub-factors based on the defined inter-dependency. 
414 For the FMEA process, three experts / decision makers (DM) deliver their judgments for six projects

415 regarding each decision variable. These decision makers were selected based on their wide experience 416 in manging large scale construction projects. The decision makers selected for this study for providing

417 pairwise comparison of different risk factors and sub-factors have more than 20 years of working 418 experience. Appendix 1 shows the fuzzy FMEA pre-defined values (FMEA reference rating scales). 419 In this phase the experts carefully consider probability, severity and number of detection parameters 420 using fuzzy linguistic variables. For example $\mathrm{DM}_{1}$ explains for project 1 corresponding $\mathrm{C}_{2}$ the severity 421 (S), probability of happening (O) and detection are $(1,1,3),(3,5,7)$ and $(1,1,3)$, respectively. Appendix 4222 presents the information of projects expressed by decision experts. Then linguistic variables are 423 translated to fuzzy values and also the defuzzification process is established.

With the help of the decision makers, pairwise comparisons are performed for the three factors to find independent weights of factors (shown in Table 3). To design Table 3, experts are asked to compare 427 three factors to realize their influence. This task is done using reference scales in Table 1. After that 428 comparison between each factor is performed with regard to the single factor. Table 3 is developed based on the experts' judgment over the importance of different risk factors. For example, as the external factors were identified 5 times more important than technical factors. Therefore, the priority 431 of technical factors over external are 0.2 times. After the pair wise comparison of each factor, sum of 432 each column is obtained. Then, each element is divided by the sum of the column. Finally, average of 433 each raw produces the weights which are seen in the last column. Similar process is followed for each 434 pairwise matrix of the decision variables. 
438 In ANP, when decision system contains factors and sub-factors, pairwise comparisons must be

439 performed in order to find importance (weight) of one over another. The weight of different factors are 440 obtained through multiplication of factors inter-dependence vector and the vector of factors 441 interrelationship with respect to each one. As there are three key decision factors ( Technical, External, 442 and Internal) in this study, four vectors (one for inter dependence and one each for three factors) should 443 be multiplied to calculate the final weight of the factor (as shown in equation 24).

444

$$
w_{\text {factors }}=\left[\begin{array}{ccc}
0.667 & 0.245 & 0.525 \\
0.15 & 0.428 & 0.334 \\
0.183 & 0.327 & 0.142
\end{array}\right] \times\left[\begin{array}{l}
0.102 \\
0.686 \\
0.211
\end{array}\right]=\left[\begin{array}{c}
0.347 \\
0.38 \\
0.273
\end{array}\right]
$$

445

446

447

448

449

450

451

452

453

454

455

456

457

458

459

460

461

462

Similarly, the pair-wise comparison of 12 sub-factors are performed to find the local-weight of each sub-factor. It is then multiplied to the weight of the corresponding risk factor ( Technical, External, or Internal - as calculated in equation 24) to generate the global weights of each sub-factors. Finally, the normalised weights of each sub-factor are presented in Table 4. The normalized global weights of subfactors are utilized in the project evaluation process by EDAS in Phase III. EDAS needs the weights of decision factors and sub-factors to find the final ranking of the projects.

$$
<<\text { Insert Table } 4 \text { about here }>>
$$

Phase III - This section ranks projects using the EDAS method. The aggregated defuzzified matrix (Appendix 3) is used as the initial decision matrix for the EDAS method. The process of ranking alternative projects using EDAS first involves developing the positive distance from average (PDA) and negative distance from average (NDA) matrices as described in equation 17 and 18 (See Appendix 4). Then, the weighted summation of the positive distance (SP) and negative distance (SN) from the average matrix are obtained (as shown in equation 19 and 20). Further, the normalised values of SP and SN for all alternatives (NSP and NSN) are calculated. Finally the appraisal scores (AS) of each alternative are computed according to equation 23. The project with highest appraisal score is 
considered as the riskiest project. The summary results obtained by the EDAS method and the ranking of the projects are presented in Table 5.

$$
<<\text { Insert Table } 5 \text { about here }>>
$$

The ranking of projects based on EDAS shows this arrangement:

Project $4>$ Project $6>$ Project $1>$ Project $3>$ Project $5>$ Project 2

Therefore, it is observed that project 4 is the riskiest project based on the judgments of experts and corresponding risk factors. Project 2 is considered as the least risky project among all. It is observed Appendix 3), that Project 4 has the maximum value regarding the criteria "subcontractors and suppliers" $\left(\mathrm{C}_{6}\right)$ which is the most important criterion among all. Also, this project has considered as one of the low cost project among others. The results are confirmed through observing the initial data. In this phase, to check the consistency and the accuracy of the obtained ranking outcomes, a comparison of the proposed approach with other popular methods is conducted. EDAS ranking scores are compared with other MCDM tools such as SAW, TOPSIS, VIKOR, COPRAS and WASPAS. The consistency of the proposed method is evident among the ranking orders of the different methods. Table 6 shows the comparative results, and tests the stability of the model.

Further, sensitivity analysis is conducted on the decision parameters to study the changes in the ranking of the projects. To conduct the sensitivity analysis, relative preferences of experts over the risk factors and sub-factors are altered and weights of decision variables are replaced by random weights. The performance of proposed approach has been then compared and analyzed for each scenario. Each scenario is represented by a "set" of alternative sub-factors weights. In total, 12 sets of weights are 
generated to analyze the impact on project ranking (as shown in figure 3). Table 7 shows the weight replacement scenarios for six projects with respect to the decision variables. Figure 3 shows that significant changes were observed in the ranking orders of the projects. Based on the sensitivity analysis outcomes, it could be concluded that on average, Project 1, Project 4, and Project 6 are the top 3 riskiest projects.

$$
<<\text { Insert Table } 7 \text { about here }>>
$$

$$
<<\text { Insert Figure } 3 \text { about here }>>
$$

\section{Discussion}

The approach proposed for the risk evaluation of projects in this study embraces multi-level internal, external and organizational factors. The proposed decision framework can help to provide suggestions and improvements for practitioners to improve their decision making capabilities. Generally the interrelationships among different levels of project evaluation are not considered by project managers. This partially blocks the decision-making process from its most accurate route and enhances the complexity of the computations. This paper essentially insists on the importance of taking into consideration such interrelationships and shows how it can be done though utilizing ANP. The proposed approach offers the additional opportunity for practitioners to express their comparisons using fuzzy linguistic values with ANP.

This paper introduces a new FMEA structure utilizing fuzzy linguistic variables. The paper argues that this novel pattern offers a unique anatomy, which increases judgment's preciseness and facilitates efficient decision-making procedure. The FMEA rating classification easily converts solid fuzzy values to the meaningful and informative codes that are exhibited in Appendix 1. Moreover, it gives reliable combination of fuzzy scales to constant alarm codes (EXH as extremely high, VH as very high). This 
513 will decrease the complexity of the judging process and allow the DM to perform a better analysis of

514 the existing project.

\section{Conclusion and future research direction}

517

518

519

520

521

522

523

524

525

526

527

528

529

530

531

532

533

534

535

536

537

Project risk management is increasingly becoming challenging due to the number of variables and parameters with quantitative and qualitative characteristics. Uncertainty and impreciseness have emerged as influential factors at the core of risk evaluation computations. Mitigating complexity, interrelationship and transaction among risk variables is a serious concern for project managers. In this paper, a new integrated model of combining FANP and FMEA in a fuzzy decision-making environment has been proposed to evaluate the potential risks of projects considering internal / organizational, external and technical factors. The ANP with fuzzy linguistic scales is applied in order to obtain relative weights of the sub-criteria and to resolve internal dependencies. In addition, failure mode and effect analysis (FMEA) has been conducted to comprehensively measure fundamental factors such as the likelihood, severity and detection of potential risk for each project. Explaining and rating these factors by verbal codes is crucial. Therefore, the utilization of fuzzy linguistic scales is appropriate to deal with such vagueness and uncertainty in comparing the priority of variables. The proposed FMEA coding improves the decision process and increases the flexibility and efficiency of risk evaluation. In this paper, decision makers offered their opinions regarding FMEA codes and then through defuzzification process, the consequences assessed by them provided the main decision matrix for MCDM process. The proposed framework provides a robust decision-making tool which can aid project managers and investors to analyze different risk factors in multiple levels of a project.

The paper contributes in developing the body of knowledge in MCDM field. A new feature is the integration of the EDAS method in to the risk evaluation process - something that was not considered in past studies. However, the study is highly reliant on the experts' opinions over the priority of the 
538 decision variables. Depending on the dimensions and levels of decision, a large pairwise comparison

539 needs to be carried out and, in such cases; fatigue is a serious concern that may cause some reliability

540 issues. In this situation, involving more decision makers in the research could be advantageous.

541 The proposed integrated MCDM model for risk evaluation can be applied to other decision-making

542 problems such as supply chain risk assessment, productivity and ergonomic risk evaluation in human

543 resource management studies. Although, ANP is a method which analyzes the interactions among 544 decision variables, it cannot recognize the direction of that interaction. In order to tackle that 545 shortcoming future research could expand the scope of this study by addressing the inter-relationships 546 among the criteria using Decision Making Trial and Evaluation Laboratory (DEMATEL) or 547 interpretive structural modeling (ISM) (Hashemi et al. 2015). Another potential improvement in the 548 project evaluation exercise could be the consideration of the risk of investment and, the satisfaction of 549 stakeholders and external customers. Integration of MCDM methods with Quality Function 550 Deployment (QFD) could be considered in future research to address this issue. Moreover, due to the 551 increasing awareness of environmental and social issues, incorporating ecological and sustainability 552 factors in the risk measurement model could be included in the proposed model.

\section{Data Availability Statement}

555 Data generated or analyzed during the study are available from the corresponding author by request. 


\section{References}

Abdi, M.R.(2009). Fuzzy multi-criteria decision model for evaluating reconfigurable machines, International Journal of Production Economics, 117(1), 1-15.

Abdi, M.R. and Labib, A.W. (2004). Feasibility study on the tactical-design justification of Reconfigurable Manufacturing Systems (RMSs) using fuzzy AHP, International Journal of Production Research, 42(15), 3055-3076.

Abdelgawad, M., \& Fayek, A. R. (2010). Risk management in the construction industry using combined fuzzy FMEA and fuzzy AHP. Journal of Construction Engineering and Management, 136(9), 1028-1036.

Andery, P. R., Vanni, C., \& Borges, G. (2000). Failure Analysis Applied To Design Optimisation. In the proceedings of the Annual Conference Of International Group For Lean Construction (Vol. 8).

Antuchevičiene, J., Zavadskas, E. K., \& Zakarevičius, A. (2010). Multiple criteria construction management decisions considering relations between criteria. Technological and Economic Development of Economy, 16(1), 109-125.

Akintoye, A. S., \& MacLeod, M. J. (1997). Risk analysis and management in construction. International Journal of project management, 15(1), 31-38.

Chan, A. P., Scott, D., \& Chan, A. P. (2004). Factors affecting the success of a construction project. Journal of construction engineering and management, 130(1), 153-155.

Chan, F.T.S. and Kumar, N. (2007). Global supplier development considering risk factors using fuzzy extended AHP-based approach. Omega: The International Journal of Management Science, 35(4) 417-431.

Chan, F. T.S., Kumar, N., Tiwari, M. K., Lau, H. C. W., and Choy, K. L. (2008). Global supplier selection: a fuzzy-AHP approach. International Journal of Production Research, 46(14), 38253857. 
Chang, D.Y., 1996, Theory and methodology: application of the extent analysis method on fuzzy AHP. European Journal of Operational Research, 95, 649-655

Chang, K. L. (2013). Combined MCDM approaches for century-old Taiwanese food firm new product development project selection. British Food Journal, 115(8), 1197-1210

Chin, K. S., Wang, Y. M., Poon, G. K. K., \& Yang, J. B. (2009). Failure mode and effects analysis using a group-based evidential reasoning approach. Computers \& Operations Research, 36(6), 1768-1779.

Dikmen, I., Birgonul, M. T., Anac, C., Tah, J. H. M., \& Aouad, G. (2008). Learning from risks: A tool for post-project risk assessment. Automation in construction, 18(1), 42-50.

Dinmohammadi, F., \& Shafiee, M. (2013). A fuzzy-FMEA risk assessment approach for offshore wind turbines. International Journal of Prognostics and Health Management, 4, 59-68.

Fallahpour, A., Amindoust, A., Antucheviciene, J., Yazdani, M. (2016). Nonlinear Genetic-Based Model for supplier selection: A comparative study, Technological and Economic Development of Economy, 22(4), 532-549

Franceschini, F., and Galetto, M. (2001). A new approach for evaluation of risk priorities of failure modes in FMEA. International Journal of Production Research, 39(13), 2991-3002.

Ghorabaee, M. K., Zavadskas, E. K., Olfat, L., and Turskis, Z. (2015). Multi-Criteria Inventory Classification Using a New Method of Evaluation Based on Distance from Average Solution (EDAS). INFORMATICA, 26(3), 435-451.

Ghorabaee, M. K., Zavadskas, E. K., Amiri, M., \& Turskis, Z. (2016). Extended EDAS Method for Fuzzy Multi-criteria Decision-making: An Application to Supplier Selection. International Journal of Computers Communications \& Control, 11(3), 358-371.

Gu, X. and Zhu, Q., 2006. Fuzzy multi-attribute decision-making method based on eigenvector of fuzzy attribute evaluation space. Decision Support Systems, 41(2), pp.400-410. 
605

606

607

608

609

610

611

612

613

614

615

616

617

618

619

620

621

622

623

624

625

626

627

628
Hashemi, S. H., Karimi, A., \& Tavana, M. (2015). An integrated green supplier selection approach with analytic network process and improved Grey relational analysis. International Journal of Production Economics, 159, 178-191.

He, Q., Luo, L., Hu, Y. and Chan, A.P. (2015). Measuring the complexity of mega construction projects in China-A fuzzy analytic network process analysis. International Journal of Project Management, 33(3), 549-563.

Ho, W., He, T., Lee, C. K. M., \& Emrouznejad, A. (2012). Strategic logistics outsourcing: An integrated QFD and fuzzy AHP approach. Expert Systems with Applications, 39(12), 1084110850.

Hu, A. H., Hsu, C. W., Kuo, T. C., \& Wu, W. C. (2009). Risk evaluation of green components to hazardous substance using FMEA and FAHP. Expert Systems with Applications, 36(3), 71427147.

Ignatius, J., Rahman, A., Yazdani, M., Šaparauskas, J., \& Haron, S. H. (2016). An integrated fuzzy ANP-QFD approach for green building assessment. Journal of Civil Engineering and Management, 22(4), 551-563.

Isaac, S., \& Navon, R. (2009). Modeling building projects as a basis for change control. Automation in Construction, 18(5), 656-664.

Kang, H. Y., Lee, A. H., \& Yang, C. Y. (2012). A fuzzy ANP model for supplier selection as applied to IC packaging. Journal of Intelligent Manufacturing, 23(5), 1477-1488.

Kerzner, H. R. (2011). Project management metrics, KPIs, and dashboards: a guide to measuring and monitoring project performance. John Wiley \& Sons.

Lavender, S. A., Mehta, J. P., \& Allread, W. G. (2013). Comparisons of tibial accelerations when walking on a wood composite vs. a concrete mezzanine surface. Applied ergonomics, 44(5), 824827 
629 Liu, H. C., Liu, L., Liu, N., \& Mao, L. X. (2012). Risk evaluation in failure mode and effects analysis

630

631

632

633

634

635

636

637

638

639

640

641

642

643

644

645

646

647

648

649

650

651

with extended VIKOR method under fuzzy environment. Expert Systems with Applications, 39(17), 12926-12934.

Liu, H. C., Liu, L., \& Liu, N. (2013). Risk evaluation approaches in failure mode and effects analysis: A literature review. Expert Systems with Applications, 40(2), 828-838.

Lowe, D. (2013) Commercial Management: Theory and Practice, John Wiley \& Sons.

Mantel Jr, S. J., Meredith, J. R., Shafer, S. M., \& Sutton, M. M. (2001). Project management in practice. Wiley.

Maytorena, E., Winch, G. M., Freeman, J., \& Kiely, T. (2007). The influence of experience and information search styles on project risk identification performance. IEEE Transactions on Engineering Management, 54(2), 315-326

Nielsen, A. (2002). Failure modes and effects analysis (FMEA) used on moisture problems. Indoor Air, 38-43.

Peng, X., and Selvachandran, G. (2017). Pythagorean fuzzy set: state of the art and future directions, Artificial Intelligence Review, 1-55.

Prakash, C., and Barua, M. K. (2016). A combined MCDM approach for evaluation and selection of third-party reverse logistics partner for Indian electronics industry. Sustainable Production and Consumption, 7, 66-78.

Saaty, T. L. (1980). The analytic hierarchy process: planning, priority setting, resources allocation. New York: McGraw.

Saaty, T. L. (1996). Multi-criteria decision making. The Analytic Hierarchy Process, Pittsburgh.

Safari, H., Faraji, Z., \& Majidian, S. (2016). Identifying and evaluating enterprise architecture risks using FMEA and fuzzy VIKOR. Journal of Intelligent Manufacturing, 27(2), 475-486. 
652 Sharma, R. K., Kumar, D., \& Kumar, P. (2005). Systematic failure mode effect analysis (FMEA) using

653

654

655

656

657

658

659

660

661

662

663

664

665

666

667

668

669

670

671

672

673

674 fuzzy linguistic modelling. International Journal of Quality \& Reliability Management, 22(9), 986-1004.

Shyur, H. J. (2006). COTS evaluation using modified TOPSIS and ANP. Applied mathematics and computation, 177(1), 251-259.

Tadić, S., Zečević, S., \& Krstić, M. (2014). A novel hybrid MCDM model based on fuzzy DEMATEL, fuzzy ANP and fuzzy VIKOR for city logistics concept selection. Expert Systems with Applications, 41(18), 8112-8128.

Tavana, M., Yazdani, M., \& Di Caprio, D. (2016). An application of an integrated ANP-QFD framework for sustainable supplier selection. International Journal of Logistics Research and Applications, 1-22.

Tsaur, S. H., and Wang, C. H. (2007). The evaluation of sustainable tourism development by analytic hierarchy process and fuzzy set theory: An empirical study on the Green Island in Taiwan. Asia Pacific Journal of Tourism Research, 12 (2), 127-145.

Tserng, H. P., Yin, S. Y., Dzeng, R. J., Wou, B., Tsai, M. D., \& Chen, W. Y. (2009). A study of ontology-based risk management framework of construction projects through project life cycle. Automation in Construction, 18(7), 994-1008.

Tzeng, G. H., Chiang, C. H., \& Li, C. W. (2007). Evaluating intertwined effects in e-learning programs: A novel hybrid MCDM model based on factor analysis and DEMATEL. Expert systems with Applications, 32(4), 1028-1044.

Wang, Y. M., Chin, K. S., Poon, G. K. K., \& Yang, J. B. (2009). Risk evaluation in failure mode and effects analysis using fuzzy weighted geometric mean. Expert systems with applications, 36(2), 1195-1207. 
675 Wheeler, D.J. 2011, Problems With Risk Priority Numbers, Quality Digest, available at : 676 https://www.qualitydigest.com/inside/quality-insider-column/problems-risk-priority-

$677 \quad \underline{\text { numbers.html }}$

678 Yang, J. L., and Tzeng, G. H. (2011). An integrated MCDM technique combined with DEMATEL for 679 a novel cluster-weighted with ANP method. Expert Systems with Applications, 38(3), 1417$680 \quad 1424$.

681 Yazdani, M. and Payam, A. F. (2015). A comparative study on material selection of 682 microelectromechanical systems electrostatic actuators using Ashby, VIKOR and 683 TOPSIS. Materials \& Design, 65, 328-334.

684 Yazdani, M., Hashemkhani Zolfani, S., and Zavadskas, E. K. (2016). New integration of MCDM 685 methods and QFD in the selection of green suppliers. Journal of Business Economics and 686 Management, 1-17.

687 Zadeh, L. A. (1965). Fuzzy sets. Information and control, 8(3), 338-353.

688 Zavadskas, E. K., Turskis, Z. and Tamošaitiene, J. (2010). Risk assessment of construction projects. 689 Journal of civil engineering and management, 16(1), 33-46.

690 Zwikael, O., \& Globerson, S. (2006). Benchmarking of project planning and success in selected 691 industries. Benchmarking: An International Journal, 13(6), 688-700. 
693 List of Figures

694

695

696

Figure 1. Three phase MCDM model for project risk evaluation problem

697 Figure 2. Risk factors and sub-factors relationship and network diagram for ANP

698 Figure 3. EDAS ranking outcomes based on different scenarios of sensitivity analysis 
705

706

707

708

709

710

711

712

713

714

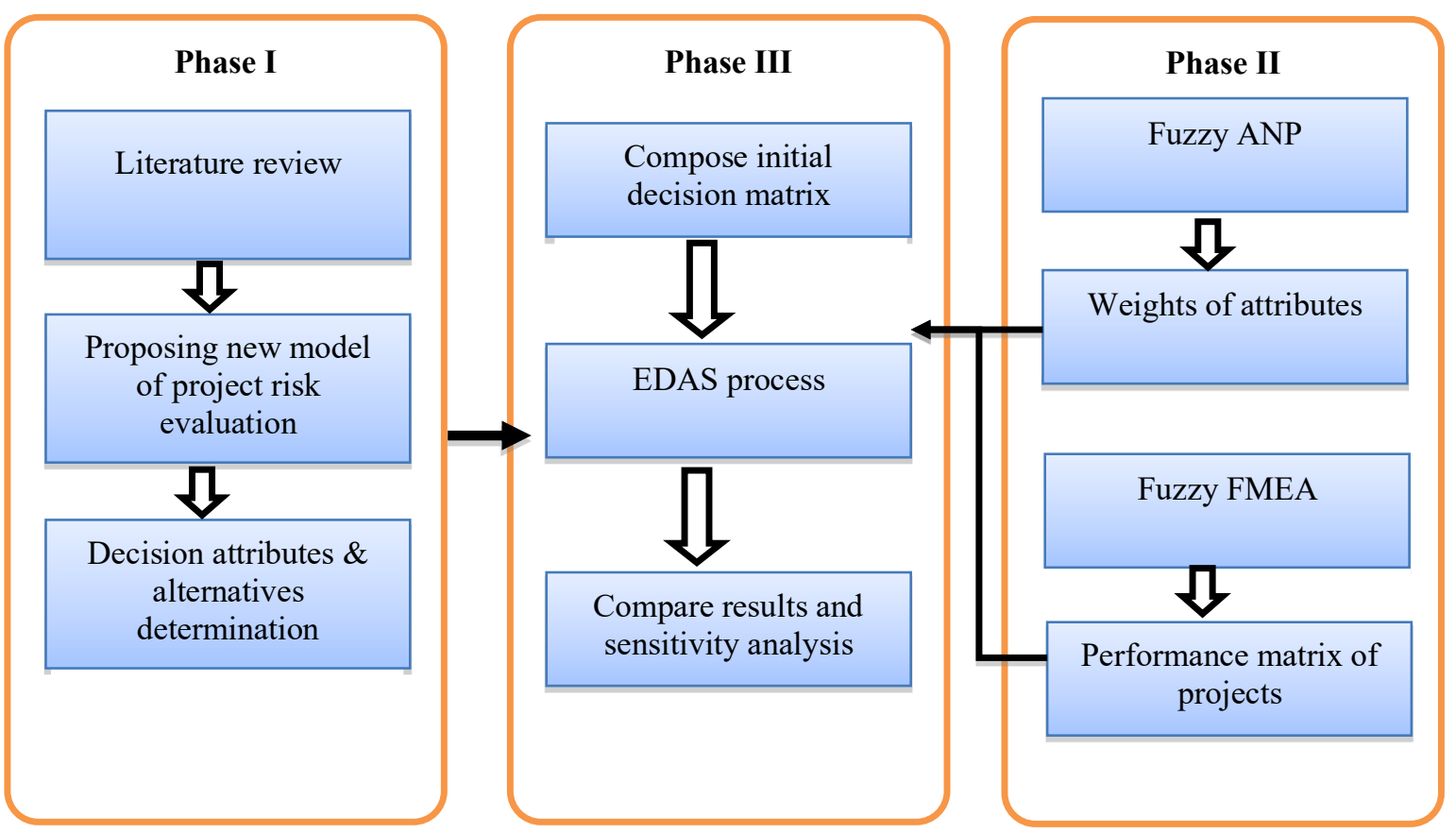

715

716

Figure 1. Three phase MCDM model for project risk evaluation problem

717 


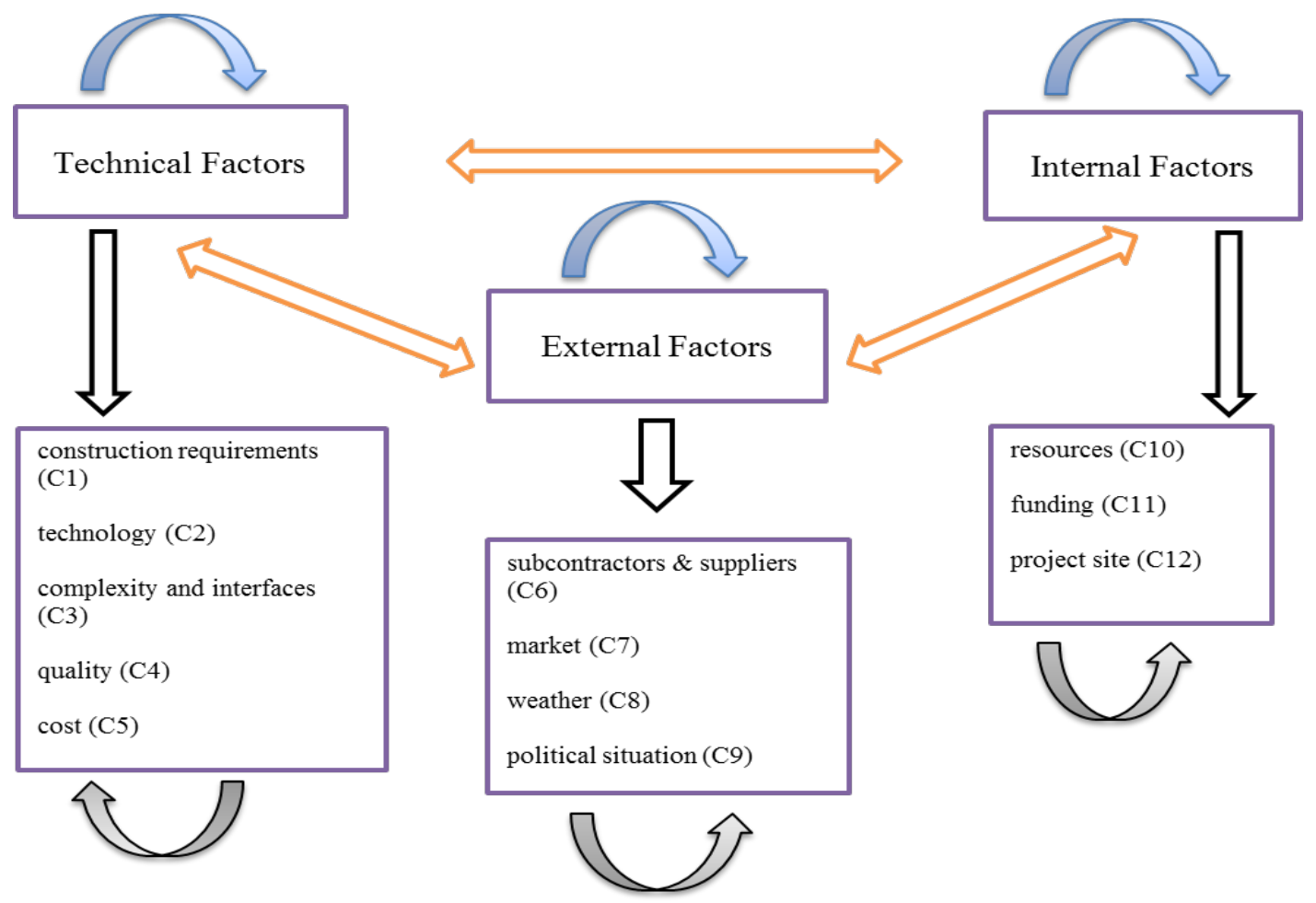

Figure 2. Risk factors and sub-factors relationship and network diagram for ANP 


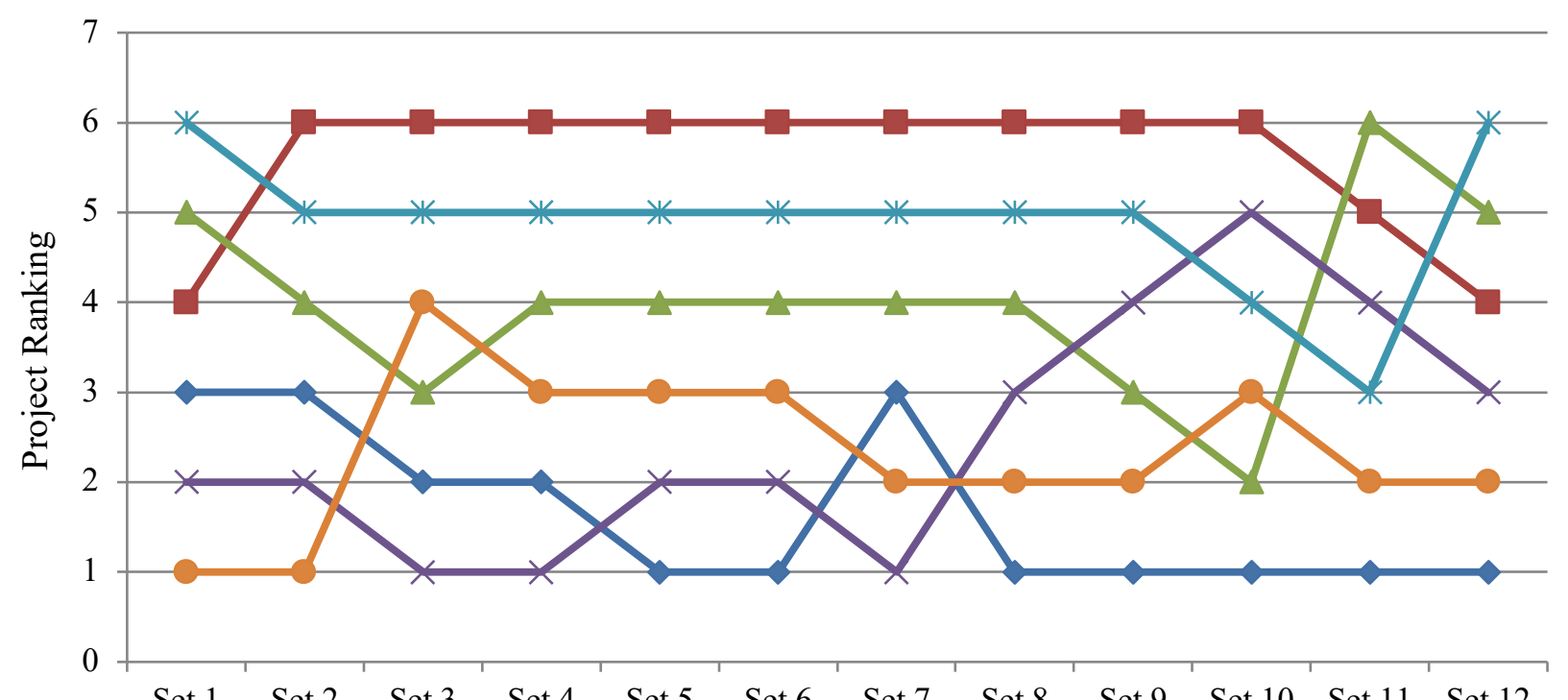

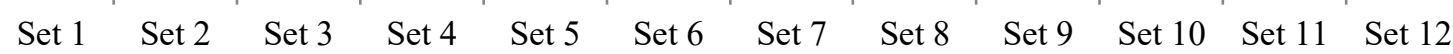

$\curvearrowleft$ Project $1 \multimap$ Project $2 \leftarrow$ Project $3 \leftarrow$ Project $4 \multimap$ Project $5 \curvearrowleft$ Project 6

Figure 3. EDAS ranking outcomes based on different scenarios of sensitivity analysis 
Table 1. Fuzzy scale for pairwise comparisons

732

\begin{tabular}{ccc}
\hline Fuzzy number & Linguistic variables & Triangular fuzzy number \\
\hline$\tilde{9}$ & Extremely important/preferred & $(7,9,9)$ \\
$\tilde{7}$ & Very strongly important/preferred & $(5,7,9)$ \\
$\tilde{5}$ & Strongly important/preferred & $(3,5,7)$ \\
$\tilde{3}$ & Moderately important/preferred & $(1,3,5)$ \\
$\tilde{1}$ & Equally important/preferred & $(1,1,3)$ \\
\hline
\end{tabular}


Table 2. Classification of fuzzy linguistic variables for RPN scoring

\begin{tabular}{|c|c|c|c|c|}
\hline $\begin{array}{c}\text { Linguistic } \\
\text { Term }\end{array}$ & $\begin{array}{c}\text { Fuzzy } \\
\text { Number }\end{array}$ & Severity & Occurrence & Detection \\
\hline Very Low & 1 & $\begin{array}{l}\text { A failure that has no/ minor } \\
\text { effect on the system } \\
\text { performance, the operator } \\
\text { probably will not notice. }\end{array}$ & $\begin{array}{l}\text { It would be very } \\
\text { unlikely for } \\
\text { these failures to } \\
\text { be observed. }\end{array}$ & $\begin{array}{l}\text { Defect remains undetected } \\
\text { until the system performance } \\
\text { degrades to the extent that } \\
\text { the task will not be } \\
\text { completed. }\end{array}$ \\
\hline
\end{tabular}

Low $\quad \hat{3} \quad$ A failure that would cause Likely to occur Defect remains undetected slight annoyance to the once, but until system performance is operator, but that cause no unlikely to severely reduced.

deterioration to the system. occur more

frequently.

Medium $\quad \hat{5} \quad$ A failure that would cause a Likely to occur Defect remains undetected high degree of operator more than once. until system performance is dissatisfaction or that affected. causes noticeable but slight deterioration in system performance.

High $\hat{7} \quad$ A failure that causes Near certain to Defect remains undetected significant deterioration in occur at least until an inspection/test is system performance and/or once. carried out. leads to minor injuries.

Very High $\quad \hat{9} \quad$ A failure that would Almost certain Failure remains undetected, seriously affect the ability to occur several until a full inspection and test to complete The task or times. is completed. cause damage, serious injury or death. 
Table 3. Pairwise comparison matrix for decision variables

\begin{tabular}{|c|c|c|c|c|c|c|c|}
\hline \multicolumn{8}{|c|}{ Comparative rating of all factors } \\
\hline Factors & Technical & External & Internal & & & & weight \\
\hline Technical & 1 & 0.2 & 0.33 & 0.1111 & 0.1429 & 0.0526 & 0.102 \\
\hline External & 5 & 1 & 5 & 0.5556 & 0.7143 & 0.7895 & 0.686 \\
\hline \multirow[t]{2}{*}{ Internal } & 3 & 0.2 & 1 & 0.3333 & 0.1429 & 0.1579 & 0.211 \\
\hline & 9 & 1.4 & 6.3 & & & & \\
\hline \multicolumn{8}{|c|}{ Relative importance of all factors with respect to technical factor } \\
\hline Technical & Technical & External & Internal & & & & weight \\
\hline Technical & 1 & 3 & 7 & 0.6774 & 0.5 & 0.8235 & 0.667 \\
\hline External & 0.33 & 1 & 0.5 & 0.2258 & 0.1667 & 0.0588 & 0.150 \\
\hline \multirow[t]{2}{*}{ Internal } & 0.14 & 2 & 1 & 0.0968 & 0.3333 & 0.1176 & 0.183 \\
\hline & 1.48 & 6 & 8.5 & & & & \\
\hline \multicolumn{8}{|c|}{ Relative importance of all factors with respect to external factor } \\
\hline External & Technical & External & Internal & & & & weight \\
\hline Technical & 1 & 0.14 & 2 & 0.1176 & 0.0455 & 0.5714 & 0.245 \\
\hline External & 7 & 1 & 0.5 & 0.8235 & 0.3182 & 0.1429 & 0.428 \\
\hline \multirow[t]{2}{*}{ Internal } & 0.5 & 2 & 1 & 0.0588 & 0.6364 & 0.2857 & 0.327 \\
\hline & 8.5 & 3.1 & 3.5 & & & & \\
\hline \multicolumn{8}{|c|}{ Relative importance of all factors with respect to internal factor } \\
\hline Internal & Technical & External & Internal & & & & weight \\
\hline Technical & 1 & 2 & 3 & 0.5455 & 0.6 & 0.4286 & 0.525 \\
\hline External & 0.5 & 1 & 3 & 0.2727 & 0.3 & 0.4286 & 0.334 \\
\hline \multirow[t]{2}{*}{ Internal } & 0.33 & 0.33 & 1 & 0.1818 & 0.1 & 0.1429 & 0.142 \\
\hline & 1.8 & 3.3 & 7 & & & & \\
\hline
\end{tabular}


748

Table 4. ANP global weights assigned for each sub-factors

\begin{tabular}{llcccc}
\hline Factors & Sub-factors (Indicators) & $\begin{array}{c}\text { Sub-factors } \\
\text { local weight }\end{array}$ & $\begin{array}{c}\text { Factors } \\
\text { weight }\end{array}$ & $\begin{array}{c}\text { Sub-factors } \\
\text { global } \\
\text { weights }\end{array}$ & $\begin{array}{c}\text { Normalized } \\
\text { global weight }\end{array}$ \\
\hline Technical & $\begin{array}{l}\text { construction requirements } \\
\left(\mathrm{C}_{1}\right)\end{array}$ & 0.0621 & 0.0215 & 0.063 \\
& $\begin{array}{l}\text { technology }\left(\mathrm{C}_{2}\right) \\
\text { complexity and interfaces } \\
\left(\mathrm{C}_{3}\right)\end{array}$ & 0.1093 & $\mathbf{0 . 3 4 7}$ & 0.0379 & 0.11 \\
& quality $\left(\mathrm{C}_{4}\right)$ & 0.0867 & & 0.0301 & 0.088 \\
& cost $\left(\mathrm{C}_{5}\right)$ & 0.0446 & 0.0155 & 0.045 \\
\hline External & $\begin{array}{l}\text { subcontractors \& suppliers } \\
\left(\mathrm{C}_{6}\right)\end{array}$ & 0.0599 & 0.1235 & 0.0208 & 0.061 \\
\hline market $\left(\mathrm{C}_{7}\right)$ & 0.1067 & $\mathbf{0 . 3 8 0}$ & 0.0405 & 0.118 \\
& weather $\left(\mathrm{C}_{8}\right)$ & 0.1006 & & 0.0382 & 0.111 \\
& political situation $\left(\mathrm{C}_{9}\right)$ & 0.0774 & & 0.0294 & 0.086 \\
\hline Internal & resources $\left(\mathrm{C}_{10}\right)$ & 0.0736 & & 0.0201 & 0.058 \\
& funding $\left(\mathrm{C}_{11}\right)$ & 0.0963 & $\mathbf{0 . 2 7 3}$ & 0.0263 & 0.077 \\
\hline project site $\left(\mathrm{C}_{12}\right)$ & 0.0594 & & 0.0162 & 0.047 \\
\hline
\end{tabular}


Table 5. Ranking of projects based on EDAS method

\begin{tabular}{lcccccc}
\hline & SP & SN & NSP & NSN & AS & RANK \\
\hline Project 1 & 0.514 & 0.366 & 0.891 & 0.477 & 0.684 & 3 \\
Project 2 & 0.200 & 0.699 & 0.347 & 0 & 0.174 & 6 \\
Project 3 & 0.317 & 0.377 & 0.549 & 0.461 & 0.505 & 4 \\
Project 4 & 0.576 & 0.294 & 1 & 0.580 & 0.790 & 1 \\
Project 5 & 0.320 & 0.406 & 0.555 & 0.420 & 0.487 & 5 \\
Project 6 & 0.525 & 0.310 & 0.911 & 0.557 & 0.734 & 2 \\
\hline
\end{tabular}

752

Table 6. Comparison of other MCDM techniques with EDAS

753

754

\section{SAW WASPAS COPRAS TOPSIS VIKOR EDAS}

\begin{tabular}{lllllll}
\hline Project 1 & 3 & 3 & 3 & 3 & 4 & 3 \\
Project 2 & 6 & 6 & 6 & 6 & 6 & 6 \\
Project 3 & 4 & 4 & 4 & 5 & 5 & 4 \\
Project 4 & 1 & 1 & 1 & 1 & 1 & 1 \\
Project 5 & 5 & 5 & 5 & 4 & 3 & 5 \\
Project 6 & 2 & 2 & 2 & 2 & 2 & 2 \\
\hline
\end{tabular}

755

Table 7. Twelve scenarios for sensitivity analysis

\begin{tabular}{ccccccccccccc}
\hline Scenarios & $\mathbf{C}_{\mathbf{1}}$ & $\mathbf{C}_{\mathbf{2}}$ & $\mathbf{C}_{\mathbf{3}}$ & $\mathbf{C}_{\mathbf{4}}$ & $\mathbf{C}_{\mathbf{5}}$ & $\mathbf{C}_{\boldsymbol{6}}$ & $\mathbf{C}_{\boldsymbol{7}}$ & $\mathbf{C}_{\mathbf{8}}$ & $\mathbf{C}_{\mathbf{9}}$ & $\mathbf{C}_{\mathbf{1 0}}$ & $\mathbf{C}_{\mathbf{1 1}}$ & $\mathbf{C}_{\mathbf{1 2}}$ \\
\hline Set 1 & 0.045 & 0.0472 & 0.0585 & 0.0605 & 0.0627 & 0.0765 & 0.0856 & 0.0877 & 0.1104 & 0.1113 & 0.1179 & 0.1366 \\
Set 2 & 0.0472 & 0.0585 & 0.0605 & 0.0627 & 0.0765 & 0.0856 & 0.0877 & 0.1104 & 0.1113 & 0.1179 & 0.1366 & 0.045 \\
Set 3 & 0.0585 & 0.0605 & 0.0627 & 0.0765 & 0.0856 & 0.0877 & 0.1104 & 0.1113 & 0.1179 & 0.1366 & 0.045 & 0.0472 \\
Set 4 & 0.0605 & 0.0627 & 0.0765 & 0.0856 & 0.0877 & 0.1104 & 0.1113 & 0.1179 & 0.1366 & 0.045 & 0.0472 & 0.0585 \\
Set 5 & 0.0627 & 0.0765 & 0.0856 & 0.0877 & 0.1104 & 0.1113 & 0.1179 & 0.1366 & 0.045 & 0.0472 & 0.0585 & 0.0605 \\
Set 6 & 0.0765 & 0.0856 & 0.0877 & 0.1104 & 0.1113 & 0.1179 & 0.1366 & 0.045 & 0.0472 & 0.0585 & 0.0605 & 0.0627 \\
Set 7 & 0.0856 & 0.0877 & 0.1104 & 0.1113 & 0.1179 & 0.1366 & 0.045 & 0.0472 & 0.0585 & 0.0605 & 0.0627 & 0.0765 \\
Set 8 & 0.0877 & 0.1104 & 0.1113 & 0.1179 & 0.1366 & 0.045 & 0.0472 & 0.0585 & 0.0605 & 0.0627 & 0.0765 & 0.0856 \\
Set 9 & 0.1104 & 0.1113 & 0.1179 & 0.1366 & 0.045 & 0.0472 & 0.0585 & 0.0605 & 0.0627 & 0.0765 & 0.0856 & 0.0877 \\
Set 10 & 0.1113 & 0.1179 & 0.1366 & 0.045 & 0.0472 & 0.0585 & 0.0605 & 0.0627 & 0.0765 & 0.0856 & 0.0877 & 0.1104 \\
Set 11 & 0.1179 & 0.1366 & 0.045 & 0.0472 & 0.0585 & 0.0605 & 0.0627 & 0.0765 & 0.0856 & 0.0877 & 0.1104 & 0.1113 \\
Set 12 & 0.1366 & 0.045 & 0.0472 & 0.0585 & 0.0605 & 0.0627 & 0.0765 & 0.0856 & 0.0877 & 0.1104 & 0.1113 & 0.1179 \\
\hline 756 & & & & & & & & & & & &
\end{tabular}

757 
Journal of Construction Engineering and Management 2019;145(5):4019-4024.

760

761

762

\begin{tabular}{cccccc}
\multicolumn{7}{c}{$\mathbf{c}$} & \multicolumn{3}{c}{ SPD } & Code & Defuzzified Value \\
\hline $\mathbf{S}$ & $\mathbf{P}$ & $\mathbf{D}$ & $\mathbf{S P D} 1$ & 600.33 \\
$(7,9,9)$ & $(7,9,9)$ & $(7,9,9)$ & $(343,729,729)$ & EXH1 & 448.33 \\
$(5,7,9)$ & $(7,9,9)$ & $(5,7,9)$ & $(175,441,729)$ & EXH2 & 448.33 \\
$(5,7,9)$ & $(5,7,9)$ & $(7,9,9)$ & $(175,441,729)$ & EXH2 & 448.33 \\
$(5,7,9)$ & $(5,7,9)$ & $(5,7,9)$ & $(45,343,729)$ & EXH3 & 372.33 \\
$(5,7,9)$ & $(3,5,7)$ & $(3,5,7)$ & $(125,175,441)$ & VH1 & 247 \\
$(3,5,7)$ & $(5,7,9)$ & $(3,5,7)$ & $(45,175,441)$ & VH2 & 220.33 \\
$(3,5,7)$ & $(3,5,7)$ & $(5,7,9)$ & $(45,175,441)$ & VH2 & 220.33 \\
$(3,5,7)$ & $(3,5,7)$ & $(3,5,7)$ & $(27,45,343)$ & H1 & 138.33 \\
$(1,3,5)$ & $(1,3,5)$ & $(3,5,7)$ & $(1,45,175)$ & H2 & 74.33 \\
$(3,5,7)$ & $(1,3,5)$ & $(1,3,5)$ & $(1,45,175)$ & H3 & 73.00 \\
$(1,3,5)$ & $(3,5,7)$ & $(1,3,5)$ & $(3,45,175)$ & H3 & 73.00 \\
$(1,3,5)$ & $(1,3,5)$ & $(1,3,5)$ & $(1,27,125)$ & M1 & 51 \\
$(7,9,9)$ & $(1,1,3)$ & $(1,1,3)$ & $(7,9,81)$ & M2 & 32.33 \\
$(1,1,3)$ & $(7,9,9)$ & $(1,1,3)$ & $(7,9,81)$ & M2 & 32.33 \\
$(1,1,3)$ & $(1,1,3)$ & $(7,9,9)$ & $(7,9,81)$ & M2 & 32.33 \\
$(3,5,7)$ & $(1,1,3)$ & $(1,1,3)$ & $(3,5,63)$ & L & 23.67 \\
$(1,1,3)$ & $(3,5,7)$ & $(1,1,3)$ & $(3,5,63)$ & L & 23.67 \\
$(1,1,3)$ & $(1,1,3)$ & $(3,5,7)$ & $(3,5,63)$ & L & 23.67 \\
$(1,3,5)$ & $(1,1,3)$ & $(1,1,3)$ & $(1,3,45)$ & VL1 & 16.33 \\
$(1,1,3)$ & $(1,3,5)$ & $(1,1,3)$ & $(1,3,45)$ & VL1 & 16.33 \\
$(1,1,3)$ & $(1,1,3)$ & $(1,3,5)$ & $(1,3,45)$ & VL1 & 16.33 \\
$(1,1,3)$ & $(1,1,3)$ & $(1,1,3)$ & $(1,1,9)$ & VL2 & 3.67 \\
\hline
\end{tabular}

Appendices:

Appendix 1: Fuzzy FMEA rating reference for projects and assigned defuzzified values 
Journal of Construction Engineering and Management 2019;145(5):4019-4024.

Appendix 2: Decision makers rating over risk factors of projects using FMEA codes

\begin{tabular}{|c|c|c|c|c|c|c|c|c|c|c|c|c|}
\hline $\mathbf{D M}_{1}$ & $\mathrm{C}_{1}$ & $\mathrm{C}_{2}$ & $\mathbf{C}_{3}$ & $\mathrm{C}_{4}$ & $\mathrm{C}_{5}$ & $\mathrm{C}_{6}$ & $\mathrm{C}_{7}$ & $\mathrm{C}_{8}$ & $\mathrm{C}_{9}$ & $\mathbf{C}_{10}$ & $\mathbf{C}_{11}$ & $\mathrm{C}_{12}$ \\
\hline Project 1 & EXH2 & $\mathrm{L}$ & H3 & M2 & VL2 & $\mathrm{L}$ & VH2 & M1 & $\mathrm{L}$ & M1 & M2 & M2 \\
\hline Project 2 & VL1 & $\mathrm{L}$ & M1 & M1 & VH1 & M1 & M2 & VL2 & VL2 & VH2 & M1 & $\mathrm{H} 2$ \\
\hline Project 3 & M1 & M1 & EXH2 & $\mathrm{L}$ & M2 & $\mathrm{L}$ & M1 & M2 & $\mathrm{H} 1$ & $\mathrm{H} 2$ & $\mathrm{~L}$ & $\mathrm{~L}$ \\
\hline Project 4 & $\mathrm{H} 2$ & $\mathrm{~L}$ & M2 & $\mathrm{H} 3$ & $\mathrm{~L}$ & EXH3 & M1 & $\mathrm{H} 2$ & $\mathrm{H} 2$ & M1 & $\mathrm{L}$ & M2 \\
\hline Project 5 & M2 & VH1 & M2 & $\mathrm{L}$ & M2 & M1 & M2 & M1 & M1 & M1 & M1 & $\mathrm{L}$ \\
\hline $\begin{array}{l}\text { Project } 6 \\
\mathbf{D M}_{2}\end{array}$ & $\mathrm{~L}$ & M2 & H1 & M1 & $\mathrm{L}$ & VH2 & VL1 & $\mathrm{H} 3$ & $\mathrm{~L}$ & $\mathrm{H} 3$ & EXH3 & VL2 \\
\hline Project 1 & EXH3 & $\mathrm{L}$ & $\mathrm{H} 2$ & M1 & VL1 & VL2 & VH1 & M2 & VL1 & M2 & M1 & M1 \\
\hline Project 2 & VL2 & VL1 & M2 & M2 & VH1 & M1 & M1 & VL1 & VL2 & VH1 & M1 & $\mathrm{H} 1$ \\
\hline Project 3 & M1 & M2 & EXH2 & $\mathrm{L}$ & M1 & VL1 & M2 & M1 & $\mathrm{H} 2$ & $\mathrm{H} 2$ & VL2 & VL1 \\
\hline Project 4 & H3 & $\mathrm{L}$ & M1 & H3 & VL1 & EXH2 & M2 & $\mathrm{H} 2$ & H1 & M2 & VL1 & M2 \\
\hline Project 5 & M1 & VH2 & M2 & VL2 & M1 & M2 & M1 & M2 & M1 & M2 & M2 & VL2 \\
\hline $\begin{array}{l}\text { Project } 6 \\
\mathbf{D M}_{3}\end{array}$ & VL1 & M2 & $\mathrm{H} 2$ & M1 & $\mathrm{L}$ & VH1 & VL2 & $\mathrm{H} 2$ & VL1 & $\mathrm{H} 2$ & EXH2 & $\mathrm{L}$ \\
\hline Project 1 & VH1 & VL2 & H1 & M1 & VL1 & VL1 & VH2 & M1 & VL2 & M1 & M1 & M2 \\
\hline Project 2 & VL1 & VL1 & M2 & M1 & VH2 & M2 & M1 & VL1 & VL2 & VH1 & M2 & $\mathrm{H} 1$ \\
\hline Project 3 & M1 & M1 & EXH3 & VL2 & M1 & VL1 & M1 & M2 & H3 & H3 & VL2 & VL2 \\
\hline Project 4 & $\mathrm{H} 2$ & $\mathrm{~L}$ & M1 & $\mathrm{H} 1$ & VL2 & EXH3 & M2 & H3 & H1 & M2 & VL2 & M2 \\
\hline Project 5 & M2 & VH1 & M1 & VL1 & M1 & M2 & M2 & M2 & M2 & M1 & M1 & VL1 \\
\hline Project 6 & VL2 & M1 & $\mathrm{H} 3$ & M2 & VL1 & VH2 & VL1 & H1 & VL2 & $\mathrm{H} 2$ & EXH1 & VL1 \\
\hline
\end{tabular}


Journal of Construction Engineering and Management 2019;145(5):4019-4024.

Appendix 3: Defuzzified aggregated decision makers judgment table (Initial decision matrix)

769

\begin{tabular}{lcccccccccccc}
\hline & $\mathbf{C}_{\mathbf{1}}$ & $\mathbf{C}_{\mathbf{2}}$ & $\mathbf{C}_{\boldsymbol{3}}$ & $\mathbf{C}_{\boldsymbol{4}}$ & $\mathbf{C}_{\mathbf{5}}$ & $\mathbf{C}_{\boldsymbol{6}}$ & $\mathbf{C}_{\mathbf{7}}$ & $\mathbf{C}_{\boldsymbol{8}}$ & $\mathbf{C}_{\mathbf{9}}$ & $\mathbf{C}_{\mathbf{1 0}}$ & $\mathbf{C}_{\mathbf{1 1}}$ & $\mathbf{C}_{\mathbf{1 2}}$ \\
\hline Project 1 & 355.89 & 17 & 95.22 & 44.78 & 12.11 & 14.56 & 229.22 & 44.78 & 14.56 & 44.78 & 44.78 & 38.55 \\
Project 2 & 12.11 & 18.78 & 38.55 & 44.78 & 238.11 & 44.78 & 44.78 & 12.11 & 3.67 & 238.11 & 44.78 & 117 \\
Project 3 & 51 & 44.78 & 423 & 17 & 44.78 & 18.78 & 44.78 & 38.55 & 95.22 & 73.89 & 10.34 & 14.56 \\
Project 4 & 73.89 & 23.67 & 44.78 & 94.78 & 14.56 & 397.66 & 38.55 & 73.89 & 117 & 38.55 & 14.56 & 32.33 \\
Project 5 & 38.55 & 238.11 & 38.55 & 14.56 & 44.78 & 38.55 & 38.55 & 38.55 & 44.78 & 44.78 & 44.78 & 14.56 \\
Project 6 & 14.56 & 38.55 & 95.22 & 44.78 & 21.22 & 229.22 & 12.11 & 95.22 & 14.56 & 73.89 & 473.66 & 14.56 \\
\hline
\end{tabular}

770

771

772

773 
774 Appendix 4: Matrices of the positive distance from average (PDA) and the negative distance from

775 average (NDA)

776

\begin{tabular}{lllllllllllll}
\hline PDA & C1 & C2 & C3 & C4 & C5 & C6 & C7 & C8 & C9 & C10 & C11 & C12 \\
\hline Project 1 & 2.9109 & 0 & 0 & 0.0307 & 0.8065 & 0 & 2.371 & 0 & 0 & 0 & 0 & 0 \\
Project 2 & 0 & 0 & 0 & 0.0307 & 0 & 0 & 0 & 0 & 0 & 1.7795 & 0 & 2.0317 \\
Project 3 & 0 & 0 & 2.4515 & 0 & 0.2846 & 0 & 0 & 0 & 0.9716 & 0 & 0 & 0 \\
Project 4 & 0 & 0 & 0 & 1.1816 & 0.7674 & 2.2089 & 0 & 0.4626 & 1.4225 & 0 & 0 & 0 \\
Project 5 & 0 & 2.7508 & 0 & 0 & 0.2846 & 0 & 0 & 0 & 0 & 0 & 0 & 0 \\
Project 6 & 0 & 0 & 0 & 0.0307 & 0.6609 & 0.8497 & 0 & 0.8849 & 0 & 0 & 3.4905 & 0
\end{tabular}

777

\begin{tabular}{lllllllllllll}
\hline NDA & C1 & C2 & C3 & C4 & C5 & C6 & C7 & C8 & C9 & C10 & C11 & C12 \\
\hline Project 1 & 0 & 0.7322 & 0.223 & 0 & 0 & 0.8825 & 0 & 0.1136 & 0.6986 & 0.4773 & 0.5755 & 0.001 \\
Project 2 & 0.8669 & 0.7042 & 0.6854 & 0 & 2.8041 & 0.6387 & 0.3415 & 0.7603 & 0.924 & 0 & 0.5755 & 0 \\
Project 3 & 0.4396 & 0.2947 & 0 & 0.6086 & 0 & 0.8485 & 0.3415 & 0.2368 & 0 & 0.1375 & 0.902 & 0.6228 \\
Project 4 & 0.188 & 0.6271 & 0.6346 & 0 & 0 & 0 & 0.433 & 0 & 0 & 0.55 & 0.862 & 0.1623 \\
Project 5 & 0.5763 & 0 & 0.6854 & 0.6649 & 0 & 0.6889 & 0.433 & 0.2368 & 0.0729 & 0.4773 & 0.5755 & 0.6228 \\
Project 6 & 0.84 & 0.3927 & 0.223 & 0 & 0 & 0 & 0.8219 & 0 & 0.6986 & 0.1375 & 0 & 0.6228 \\
\hline
\end{tabular}

778

779

780 